\title{
Functional relationship between cathodic protection current/potential and duration of system deployment in desert conditions
}

\author{
A. Muharemovic, I. Turkovic \& S. Bisanovic \\ University of Sarajevo, Department of Electrical Engineering, \\ Bosnia and Herzegovina
}

\begin{abstract}
This paper analyzes the attenuation of cathodic protection (CP) current/potential in pre-stressed concrete cylinder pipes while using galvanic anodes during system employment. The focus in this paper is on the functional relationship between CP current/potential and the duration of system employment in desert conditions. The purpose of this paper is to reach an approximate formula for the functional relationship current/potential following a deployment of a CP system. Consequently, costly field measurements of said PCCP current/potential can be avoided, thus rendering a more efficient operation of the $\mathrm{CP}$ system. These measurements have been taken in desert conditions in sections with very high and low soil resistivity during 22 months. Field measurements confirm that there is a substantial reduction of CP current magnitude following initial CP system deployment. Field data confirm the existence of the correlation between $\mathrm{CP}$ current and the time of system exploitation, until the point where full system polarization occurs. For both values of soil resistivity, based on measured current values over time, the paper presents a regression model that is a determined twoterm exponential equation.
\end{abstract}

Keywords: cathodic protection, correlation model, cylinder pipes, protection current, measurements, desert conditions.

\section{Introduction}

In this paper we analyze the attenuation of cathodic protection (CP) current/potential in conditions of high and low soil resistivity that are typical for 
desert oasis environments. Our study focuses on cases where CP has been applied to pre-stressed concrete cylinder pipes (PCCP) while using galvanic anodes. We present a functional dependency between $\mathrm{CP}$ current/potential and the duration of system deployment for cases of high and low soil resistivity. We conclude that total polarization occurs after approximately six months of system deployment, which is the time needed for polarization of bare steel structures in the electrolyte with low soil resistivity. The results have both technical and commercial value, since they make long-term field measurements no longer necessary. The derived dependency between CP current/potential and the duration of system deployment enables a more accurate computation of current/potential parameters in $\mathrm{CP}$ systems.

The attenuation of the protection current, until the point of full PCCP polarization in the CP system, is caused by [1-5]:

- $\quad$ polarization of the PCCP;

- $\quad$ partial wear of the cast zinc anode as a result of CP system operation;

- $\quad$ increase of anode resistance $\mathrm{R}_{\mathrm{A}}$ during system operation.

Purpose of this paper is reaching an approximate formula for the polarization current/potential following a deployment of a CP system. Consequently, costly field measurements of said PCCP current/potential can be avoided, thus rendering a more efficient operation of the $\mathrm{CP}$ system.

\section{Experimental basis and functional correlation}

A computerized statistical method that calculates current/potential as functional correlation of duration based on measurement data for CP system is introduced. The method uses the regression and correlation analysis of measurements of current and potentials of the piping network in desert environment. This approach ensures during the time installation of more CP capacity with distributed anodes around the piping network and examination of the protection potentials without need for new expensive measurements. This procedure is recommended for the improvement of the existing and new CP system.

Based on this approach, developed program determines the relationship between two or more variables from a group of known values from such variables using regression and correlation analysis. The main objective of the program is, with a set of data and based in a curve as a model, to use the regression analysis to obtain the coefficients of the curve to fit the best correlation (minimal standard deviation) between the mathematical model and the set of known data.

\subsection{The measured values and functional relationship for high soil resistivity}

For high soil resistivity we have measured values of the grounded current over time as presented in Table 1. Measured values are given for several points. Also, in Table 2 are given measured values changes of polarization potential over time. Graphical illustration of the change in current over time is presented in Figure 1. 
Table 1: $\quad$ The change in the grounded current over time [6,7].

\begin{tabular}{|c|c|c|c|c|c|}
\hline section & st $224+240$ & st $224+850$ & st $225+420$ & st 226+020 & st 228+950 \\
\hline $\mathrm{t}[$ days] & $\mathrm{I}[\mathrm{A}]$ & $\mathrm{I}[\mathrm{A}]$ & $\mathrm{I}[\mathrm{A}]$ & $\mathrm{I}[\mathrm{A}]$ & $\mathrm{I}[\mathrm{A}]$ \\
\hline 10 & 1,36 & 1,26 & 1,08 & 1,06 & 1,08 \\
\hline 70 & 1,23 & 1,06 & 1,00 & 1,00 & 1,00 \\
\hline 160 & 1,18 & 0,96 & 0,94 & 0,94 & 0,96 \\
\hline 250 & 1,06 & 0,84 & 0,86 & 0,82 & 0,82 \\
\hline 340 & 0,95 & 0,70 & 0,78 & 0,70 & 0,68 \\
\hline 410 & 0,84 & 0,54 & 0,68 & 0,62 & 0,60 \\
\hline 530 & 0,74 & 0,44 & 0,58 & 0,54 & 0,52 \\
\hline 620 & 0,70 & 0,40 & 0,52 & 0,46 & 0,48 \\
\hline 710 & 0,68 & 0,40 & 0,50 & 0,45 & 0,47 \\
\hline$\rho[\Omega \mathrm{m}]$ & 860 & 875 & 1030 & 1170 & 970 \\
\hline
\end{tabular}

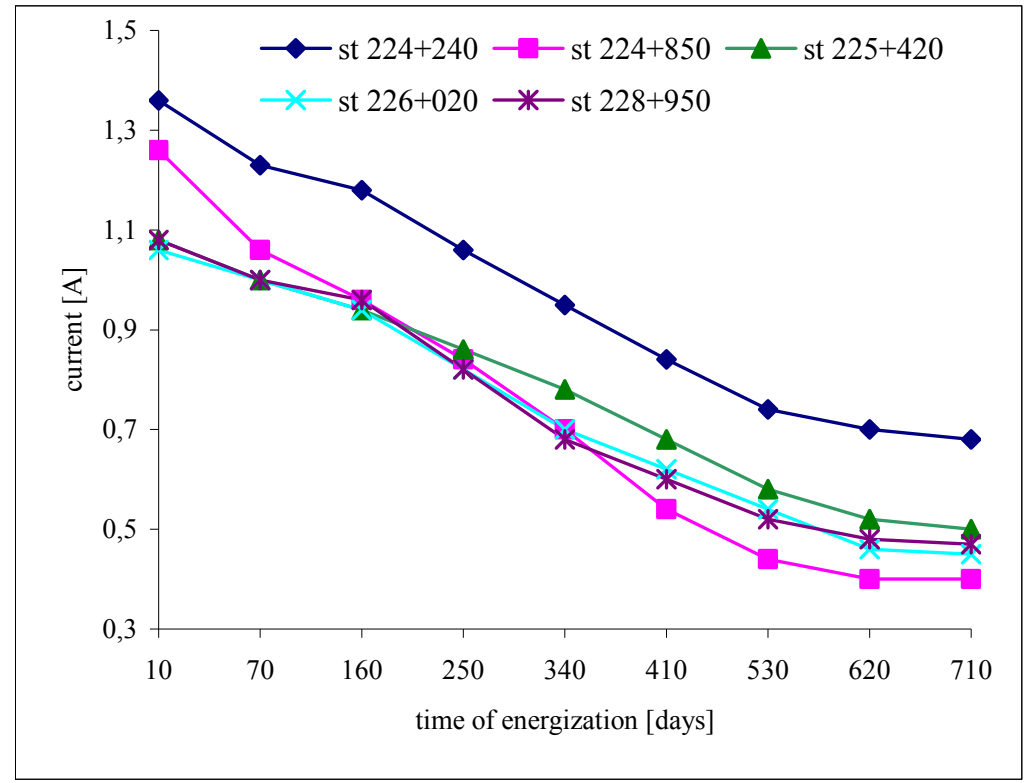

Figure 1: The change in current over time.

On the basis of the measured values of current over time, presented in Table 1, a sample correlation of the results was conducted so as to obtain the functional relationship of the current change over time. To express correlation, we select an exponential regression line: 
62 Simulation of Electrochemical Processes III

Table 2: $\quad$ Changes of polarization potential over time $[6,7]$.

\begin{tabular}{|c|c|c|c|c|c|}
\hline section & $\begin{array}{c}\mathrm{st} \\
224+240\end{array}$ & $\begin{array}{c}\mathrm{st} \\
224+850\end{array}$ & $\begin{array}{c}\mathrm{st} \\
225+420\end{array}$ & $\begin{array}{c}\mathrm{st} \\
226+020\end{array}$ & $\begin{array}{c}\mathrm{st} \\
228+950\end{array}$ \\
\hline $\mathrm{V}_{\text {natural }}$ & $-23[\mathrm{mV}]$ & $-47[\mathrm{mV}]$ & $-32[\mathrm{mV}]$ & $-42[\mathrm{mV}]$ & $-15[\mathrm{mV}]$ \\
\hline $\mathrm{t}[$ days $]$ & $-\mathrm{V}[\mathrm{mV}]$ & $-\mathrm{V}[\mathrm{mV}]$ & $-\mathrm{V}[\mathrm{mV}]$ & $-\mathrm{V}[\mathrm{mV}]$ & $-\mathrm{V}[\mathrm{mV}]$ \\
\hline 10 & 429 & 302 & 380 & 228 & 612 \\
\hline 70 & 442 & 295 & 365 & 242 & 618 \\
\hline 160 & 491 & 332 & 375 & 298 & 602 \\
\hline 250 & 430 & 265 & 341 & 284 & 476 \\
\hline 340 & 328 & 196 & 286 & 268 & 370 \\
\hline$\rho[\Omega \mathrm{m}]$ & 860 & 875 & 1030 & 1170 & 970 \\
\hline
\end{tabular}

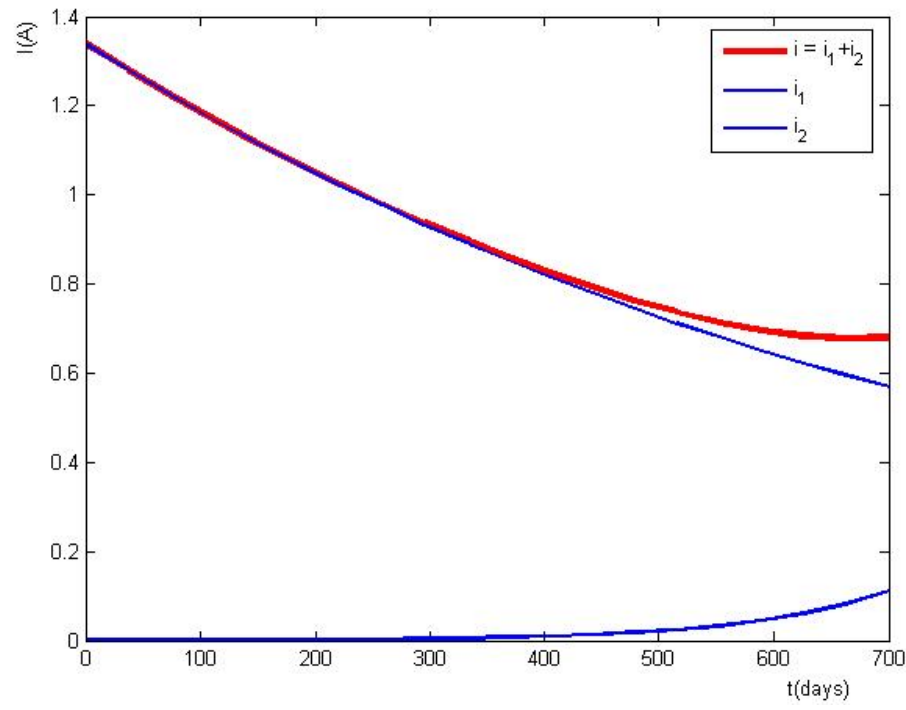

Figure 2: $\quad$ Regression curve for st $224+240$.

$$
I=I_{01} e^{-a t}+I_{02} e^{b t}
$$

An example of the regression curve for st $224+240(\rho=860[\Omega \mathrm{m}])$ is given in Figure 2.

For this section, the functional relationship is:

$$
I=1,374972 e^{-0,001150 t}+0,000124 e^{0,008793 t}
$$


In the case of nonlinear regression, following formula is used to determine the correlation coefficient:

$$
k=\sqrt{1-\frac{s_{y}^{2}}{\sigma_{y}^{2}}}=\sqrt{1-\frac{\sum\left(y_{m}-y_{r}\right)^{2}}{\sum\left(y_{m}-\bar{y}\right)^{2}}}
$$

where:

- $\quad y_{m}$ - the measured values of the current at given points;

- $\quad y_{r}-$ the values of current at given points, calculated with regression curve;

$-\quad \bar{y}=\frac{1}{n} \sum_{i=1}^{n} y_{i m}-$ the sample mean of the measured values of current at given points.

Values of the correlation coefficient $k$ that are close to 1 indicate that the selected regression curve is in close proximity to the measured data. In that case, we say that there is high stochastic nonlinear relationship between the varying values.

Another factor that can determine the quality of the stochastic correlation of results is the standard deviation $s$ of the random error component of the measurement results. This is calculated as follows:

$$
s=\sqrt{\frac{1}{n-1} \sum_{i=1}^{n}\left(y_{r}-\bar{y}\right)^{2}}
$$

The values of the standard deviation that are close to 0 indicate that the chosen model has a small random error component and that the regression was done properly. In case st $224+240$, these factors are $k=0,995124$ and

Table 3: $\quad$ Coefficients for the correlation function for given sections.

\begin{tabular}{|c|c|c|c|c|c|c|}
\hline section & $I_{01}$ & $I_{02}$ & $a$ & $b$ & $k$ & $s$ \\
\hline $\begin{array}{c}\text { st } \\
224+240\end{array}$ & 1,374972 & 0,000124 & 0,001150 & 0,008793 & 0,995124 & 0,024634 \\
\hline $\begin{array}{c}\text { st } \\
224+850\end{array}$ & 1,193506 & 0,075234 & 0,002043 & 0,000042 & 0,991874 & 0,040072 \\
\hline $\begin{array}{c}\text { st } \\
225+420\end{array}$ & 1,399827 & $-0,306529$ & 0,000744 & 0,000194 & 0,995527 & 0,020199 \\
\hline $\begin{array}{c}\text { st } \\
226+020\end{array}$ & 1,165009 & $-0,107443$ & 0,001445 & $-0,015353$ & 0,996517 & 0,019431 \\
\hline $\begin{array}{c}\text { st } \\
228+950\end{array}$ & 1,121880 & 0,000002 & 0,001416 & 0,014730 & 0,991647 & 0,030585 \\
\hline
\end{tabular}


$s=0,024634$, which suggests that the functional relationship between protection current and time of polarization is almost complete. Table 3 gives the coefficients for the correlation function for specific sections.

Table 4: The change in the grounded current over time [6,7].

\begin{tabular}{|c|c|c|c|c|c|}
\hline section & $\begin{array}{c}\text { st } \\
261+660\end{array}$ & $\begin{array}{c}\text { st } \\
262+270\end{array}$ & $\begin{array}{c}\text { st } \\
262+870\end{array}$ & $\begin{array}{c}\text { st } \\
263+340\end{array}$ & $\begin{array}{c}\text { st } \\
263+960\end{array}$ \\
\hline $\mathrm{t}[$ days $]$ & $\mathrm{I}[\mathrm{A}]$ & $\mathrm{I}[\mathrm{A}]$ & $\mathrm{I}[\mathrm{A}]$ & $\mathrm{I}[\mathrm{A}]$ & $\mathrm{I}[\mathrm{A}]$ \\
\hline 10 & 4,18 & 4,72 & 3,82 & 4,00 & 3,98 \\
\hline 70 & 2,50 & 3,10 & 2,30 & 2,55 & 2,10 \\
\hline 160 & 1,75 & 2,44 & 1,78 & 1,95 & 1,55 \\
\hline 250 & 1,40 & 2,20 & 1,50 & 1,65 & 1,35 \\
\hline 340 & 1,14 & 2,00 & 1,25 & 1,44 & 1,18 \\
\hline 410 & 1,00 & 1,85 & 1,12 & 1,30 & 1,02 \\
\hline 530 & 0,92 & 1,75 & 1,11 & 1,22 & 0,91 \\
\hline 620 & 0,90 & 1,73 & 1,10 & 1,21 & 0,85 \\
\hline 710 & 0,89 & 1,72 & 1,10 & 1,20 & 0,84 \\
\hline$\rho[\Omega \mathrm{m}]$ & 35 & 30 & 25 & 35 & 40 \\
\hline
\end{tabular}

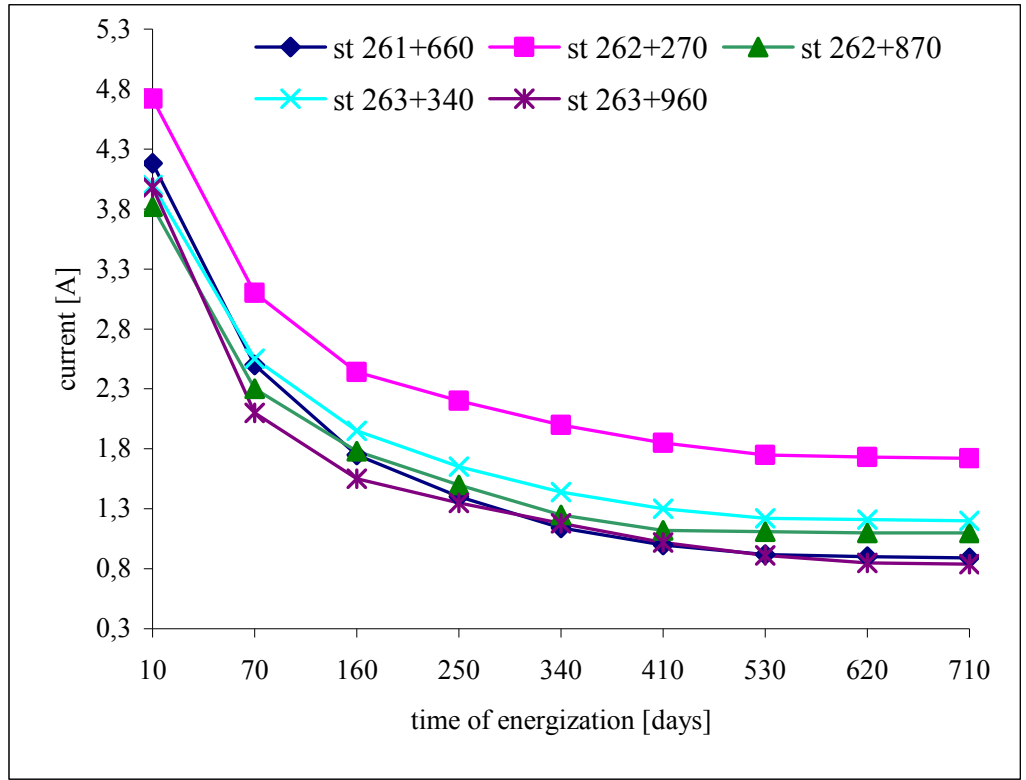

Figure 3: $\quad$ The change in current over time. 
Table 5: $\quad$ Changes of polarization potential over time $[6,7]$.

\begin{tabular}{|c|c|c|c|c|c|}
\hline section & $\begin{array}{c}\mathrm{st} \\
261+660\end{array}$ & $\begin{array}{c}\mathrm{st} \\
262+270\end{array}$ & $\begin{array}{c}\mathrm{st} \\
262+870\end{array}$ & $\begin{array}{c}\mathrm{st} \\
263+340\end{array}$ & $\begin{array}{c}\mathrm{st} \\
263+960\end{array}$ \\
\hline $\mathrm{V}_{\text {natural }}$ & $-8[\mathrm{mV}]$ & $-10[\mathrm{mV}]$ & $-13[\mathrm{mV}]$ & $-7[\mathrm{mV}]$ & $-10[\mathrm{mV}]$ \\
\hline $\mathrm{t}[$ days $]$ & $-\mathrm{V}[\mathrm{mV}]$ & $-\mathrm{V}[\mathrm{mV}]$ & $-\mathrm{V}[\mathrm{mV}]$ & $-\mathrm{V}[\mathrm{mV}]$ & $-\mathrm{V}[\mathrm{mV}]$ \\
\hline 0 & 560 & 615 & 624 & 540 & 552 \\
\hline 20 & 570 & 585 & 565 & 529 & 523 \\
\hline 80 & 480 & 545 & 435 & 454 & 440 \\
\hline 250 & 387 & 430 & 352 & 389 & 370 \\
\hline 340 & 327 & 354 & 283 & 314 & 306 \\
\hline$\rho[\Omega \mathrm{m}]$ & 35 & 30 & 25 & 35 & 40 \\
\hline
\end{tabular}

The contribution of the second factor of regression equation during the first year of operation of the CP system does not surpass the value of $2 \%$ of total protection current. Thus, we can ignore the second factor in the regression equation during the first year of operation, without any significant effect on the accuracy of results. If we analyze the data in Table 3 we see that the $\mathrm{I}_{02}$ and $\mathrm{b}$ coefficients in regression function are becoming more significant when the values of protection potential fall below the allowed protection level. This coefficient becomes important only when we have low resistivity of surrounding soil or a prolonged period of operation of the CP system.

This computerized method can be run on a personal computer and can provide timely design support and aids the professional designer in predicting, with a greater degree of certainty, the performance of CP systems.

\subsection{The measured values and functional relationship for low soil resistivity}

For low soil resistivity we have measured values of the grounded current over time as presented in Table 4. Measured values are given for several points. Also, in Table 5 are given measured values changes of polarization potential over time. Graphical illustration of the change in current over time is presented in Figure 3.

Table 6 gives the coefficients of correlation function for specific sections. If we analyze the data in Table 6 , we can see that the $\mathrm{I}_{01}$ and $a$ coefficients in regression function are becoming more significant when the values of protection potential fall below the allowed protection level. This coefficient becomes important only when we have a low soil resistivity or a prolonged period of operation of the CP system. On the basis of the measured values of current over time, presented in Table 4, a sample correlation of the results was conducted so as to obtain the functional relationship of the current change over time. To express correlation, we select an exponential regression line:

$$
I=I_{01} e^{-a t}+I_{02} e^{b t}
$$


Table 6: Coefficients for the correlation function for given sections.

\begin{tabular}{|c|c|c|c|c|c|c|}
\hline section & $I_{01}$ & $I_{02}$ & $a$ & $b$ & $k$ & $s$ \\
\hline $\begin{array}{c}\text { st } \\
261+660\end{array}$ & 2,973364 & 1,614316 & 0,014779 & $-0,000966$ & 0,998193 & 0,065652 \\
\hline $\begin{array}{c}\text { st } \\
262+270\end{array}$ & 2,748315 & 2,417513 & 0,017469 & $-0,000544$ & 0,998371 & 0,056016 \\
\hline $\begin{array}{c}\text { st } \\
262+870\end{array}$ & 2,555295 & 1,648338 & 0,016530 & $-0,000682$ & 0,995738 & 0,083149 \\
\hline $\begin{array}{c}\text { st } \\
263+340\end{array}$ & 2,515544 & 1,841271 & 0,015385 & $-0,000693$ & 0,997693 & 0,062871 \\
\hline $\begin{array}{c}\text { st } \\
263+960\end{array}$ & 1,777417 & 2,875912 & 0,001187 & $-0,025777$ & 0,999124 & 0,042028 \\
\hline
\end{tabular}

The conclusions we have made about changes in protection current values can be used effectively in the periodical recording of $\mathrm{CP}$ parameters in similar facilities, which cannot be considered as being isolated by means of a proper passive isolation. This is a simpler and more efficient way to reach valuable and realistic conclusions, especially in difficult climates, about:

- $\quad$ a realistic calculation of CP system lifetimes (seeing as the protection current decreases, as does the driving voltage),

- a realistic calculation of anode grounded configuration from the viewpoint of anode/solution resistance, considering that there is a decrease of total protection current,

- an estimation of the length of protective zone (a decrease of protection current and PCCP potential),

- $\quad$ the elimination of costly and long measurements, CIPS recording, as the values of protection current can be determinate at any moment during the time of exploitation of the CP system

Naturally, the defining of approximate analytical equations to express the functional relationship of changes in potential and in protection current values during the time of exploitation, are followed by appropriate recordings on the concrete object installed in desert ambient [6-9].

\section{Conclusion}

Extensive and cost - intensive field measurements confirm that there is a substantial reduction of CP current magnitude following initial CP system deployment. Thus, there exists a need for repetitive field measurements in order to establish and confirm the scope of $\mathrm{CP}$ protection for the object of interest $[10,11]$. Field data shown in this paper confirm the existence of the correlation between CP current and duration of system deployment, until the point where full system polarization occurs. Specifically, the case of extreme desert conditions necessitates a high soil resistivity, where the $\mathrm{CP}$ current decays 
exponentially with the duration of deployment. The same conclusion can be applied in case low soil resistivity, but with other functional relationship. This paper provides a set of parameters which enables a computation of $\mathrm{CP}$ current at any point of system deployment thus enabling $\mathrm{CP}$ system architects to estimate the CP current without making expensive filed measurements.

\section{References}

[1] A. Muharemovic, Electric power system and environment, Sarajevo, 1996.

[2] J. Morgan, Cathodic protection, Second edition, published by National Association of Corrosion Engineers, Houston, Texas, 1993.

[3] W. Baeckmann, W. Schwenk \& W. Prinz, Handbook of cathodic corrosion protection, Gulf Publishing Company, Houston, Texas, 1997.

[4] A. W. Peabody, Control of pipeline corrosion, Second edition, published by National Association of Corrosion Engineers, Houston, Texas, 2001.

[5] L. Lazzari \& P. Pedeferri, Cathodic protection, Polipress, Milano, 2006.

[6] Energoinvest Sarajevo, External cathodic protection system - scope of work, 19051-S-395-10-MC-0028-00, Sarajevo, 2006.

[7] Energoinvest Sarajevo, Potential survey procedure, 19051-S-395-10-MC0028-00, Sarajevo, 2006.

[8] Energoinvest Sarajevo, External cathodic protection project for PCCP, Operation \& maintenance period final report, 19051-S-395-10-MC-002800, 2006.

[9] A. Muharemovic, I. Turkovic \& A. Kamenica: Basic specifics for the assessment of Zinc anode strings for cathodic protection, 13th International expert meeting Power Engineering, Maribor, 2004.

[10] NACE Standard RP 0187, Design considerations for corrosion control of reinforcing steel in concrete, NACE Int., Houston, Texas, 2000.

[11] NACE Standard RP 0169, Control of external corrosion on underground or submerged metallic piping systems, NACE Int., Houston, Texas, 1996. 